\title{
Meta-Analysis of the Hemodynamic Properties of Antihypertensive Medications
}

\author{
Imran Hasan Iftikhar, ${ }^{1}$ Robert P. Blankfield, ${ }^{2,3}$ Nauman Hassan, ${ }^{4}$ and Daniel Tisch ${ }^{5}$ \\ ${ }^{1}$ Department of Medicine, School of Medicine, University of South Carolina, One Richland Medical Park, Suite 300, \\ Columbia, SC 29203, USA \\ ${ }^{2}$ Department of Family Medicine, Case Western Reserve University School of Medicine, Cleveland, OH 44106, USA \\ ${ }^{3}$ University Hospitals Medical Practice, Berea Health Center, 201 Front Street, Berea, OH 44017, USA \\ ${ }^{4}$ Pakistan Atomic Energy Hospital, Islamabad, Pakistan \\ ${ }^{5}$ Center for Global Health and Diseases, Case Western Reserve University, Cleveland, OH 44106, USA
}

Correspondence should be addressed to Imran Hasan Iftikhar; imran.iftikhar@uscmed.sc.edu

Received 16 August 2012; Accepted 6 September 2012

Academic Editors: C. Saha and B. Waeber

Copyright (c) 2013 Imran Hasan Iftikhar et al. This is an open access article distributed under the Creative Commons Attribution License, which permits unrestricted use, distribution, and reproduction in any medium, provided the original work is properly cited.

Background. While all antihypertensive medications lower blood pressure, hemodynamic properties of various classes of antihypertensive medications may differ. Objective. To perform a meta-analysis to compare the hemodynamic properties of different classes of antihypertensive medications. Methods. Studies involving the treatment of hypertension using the effect of ACEIs, $\beta$-blockers, CCBs and thiazide diuretics on plasma volume (PV), cardiac output (CO) or stroke volume (SV) were searched using online databases prior to May 2011. Studies had to be written in the English language, studying human subjects with a single pharmacological agent (monotherapy), and with a minimum duration of 4 weeks. Results. Seventy-five (75) studies that enrolled a total of 1522 subjects were included. All four antihypertensive classes lowered blood pressure. $\beta$-blockers decreased heart rate; the other classes had no effect upon heart rate. ACEIs increased PV; the other classes had no effect upon PV. $\beta$-blockers and thiazide diuretics decreased $\mathrm{CO}$ while ACEIs and CCBs had no effect upon CO. $\beta$-blockers and CCBs increased SV, thiazide diuretics decreased SV, and ACEIs did not change SV. Conclusion. In the treatment of uncomplicated hypertension, the various classes of antihypertensive medications differ from each other in terms of their non-blood pressure lowering hemodynamic properties.

\section{Introduction}

While all antihypertensive medications lower blood pressure, the non-blood-pressure-lowering hemodynamic properties of the various classes of antihypertensive medications may differ. Numerous studies documenting the effects of different antihypertensive medications upon heart rate (HR), plasma volume (PV), cardiac output (CO), and stroke volume (SV) have been published, but the sample sizes of most of these studies have been small, typically less than 20 subjects each. Differences in hemodynamic properties that distinguish one class of antihypertensive medication from another might not be evident in studies with such small samples. Furthermore, if there are differences in hemodynamic properties among the different classes of antihypertensive drugs, such differences might help clinicians customize the selection of drugs for individual patients.

We performed this meta-analysis in order to clarify and compare the hemodynamic properties of four different classes of antihypertensive medications: angiotensin converting enzyme inhibitors (ACEIs), $\beta$-adrenergic receptor antagonists ( $\beta$-blockers), calcium channel blockers (CCBs), and thiazide diuretics.

\section{Methods}

2.1. Search Strategy and Selection Criteria. Investigators (I. H. Iftikhar, R. P. Blankfield, N. Hassan) searched Pubmed for 
trials that evaluated the hemodynamic properties of the following classes of antihypertensive drugs: ACEIs, $\beta$-blockers, CCBs and thiazide diuretics. We chose these medications because there is more hemodynamic data regarding these agents than other classes of antihypertensive drugs. Boolean operators (AND, OR) were used to combine the Medical Subject Heading (MeSH) text terms for the antihypertensive classes and the hemodynamic variables. In order to ensure that all relevant articles were identified, additional searches for individual antihypertensive medications in each class were performed, and each individual medication was paired with one of the several hemodynamic variables in sequential fashion. Specifically, each drug was paired with the term "hypertension" along with either "plasma volume," "cardiac output," "stroke volume," or "hemodynamics," and a search was made for each of these pairings. In this manner, searches were made for all common drug names in each class (Table 1). Studies published prior to May 2011 were eligible for inclusion. Reference lists of all identified articles were searched for additional articles that did not appear in the database searches. No attempt to identify unpublished studies was undertaken, and no attempt was made to contact authors.

Once potentially relevant articles were identified by the initial search, two investigators (I. H. Iftikhar, R. P. Blankfield) independently evaluated studies for inclusion. Inclusion criteria were: (1) the published article had to be written in the English language, (2) the study had to include only human subjects with uncomplicated hypertension, (3) the study drug had to be administered only through the oral route, (4) a single pharmacological agent (monotherapy) was used to treat the hypertension, and (5) the duration of the study had to be a minimum period of 4 weeks. Studies were included if they contained data regarding PV, CO, and/or SV. Studies that provided data on cardiac index or stroke index were included if there was enough information to calculate CO or SV. Studies in which subjects used different antihypertensive medications at different times, but not simultaneously, were included. All case reports, case series, and review articles were excluded. Studies that included subjects with diabetes mellitus, heart failure, or coronary artery disease were excluded. If multiple publications of the same trial were identified, only the most recent publication was chosen for inclusion. Studies that did not include standard deviation data were excluded. Disagreements were resolved through discussion among reviewers.

2.2. Data Extraction. For studies that met the inclusion criteria, extracted data included the first author's name, year of publication, number of subjects, pre- and posttreatment mean arterial pressure with standard deviations, pre- and posttreatment mean HR with standard deviations, pre- and posttreatment mean PV with standard deviations, pre- and posttreatment mean $\mathrm{CO}$ with standard deviations, and preand posttreatment mean SV with standard deviations. For studies that reported mean systolic and mean diastolic blood pressures but not mean arterial pressures, mean arterial pressures were calculated. Data was extracted from articles that reported mean cardiac index (CI) or mean stroke index

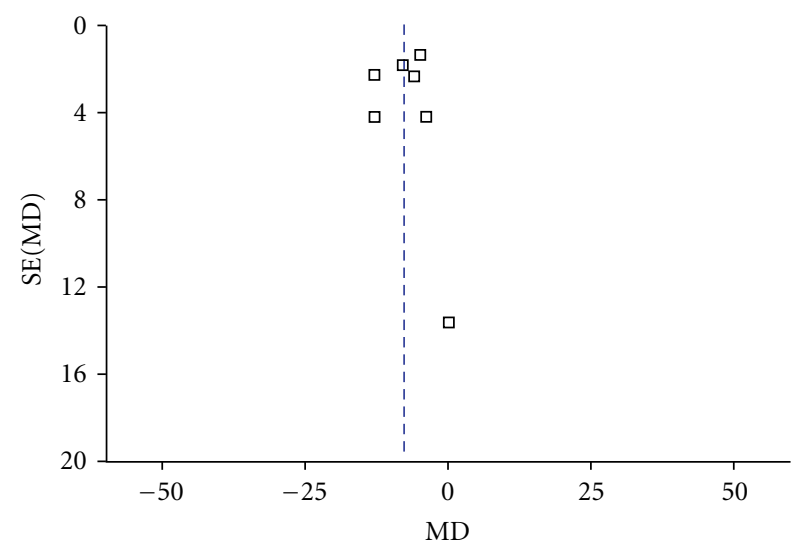

SE indicates standard error of mean $\mathrm{MD}$ indicates mean difference

Figure 1: Funnel plot of stroke volume changes for thiazide diuretics.

(SI) only if mean CO and/or mean SV could be calculated based upon mean body surface area data or mean height and weight data. This method of calculating $\mathrm{CO}$ or SV provides an approximation to the individual data [1]. We chose to use CO and SV rather than $\mathrm{CI}$ and SI because there was considerably more data available for $\mathrm{CO}$ and SV than there was for $\mathrm{CI}$ and SI. All included studies were peer reviewed and were assumed to represent valid information regarding drug effect.

2.3. Quantitative Data Synthesis. The absolute effectiveness of each drug regimen was quantified by estimating the mean difference of outcomes before and after intervention. Effectiveness was pooled across studies using the DerSimonian and Laird random effects meta-analyses models.

Heterogeneity was assessed with $I^{2}$ index and the tausquared test. To assess the risk of publication bias, funnel plots of standard error and difference in means were constructed. A funnel plot of the SV data for thiazide diuretics (Figure 1) is representative of the funnel plot data. NCSS software version 2007 was used to analyze the data.

\section{Results}

3.1. Trial Flow. A total of 227 potentially relevant articles were identified, of which 152 were excluded, primarily due to insufficient outcome data. Figure 2 summarizes the results of the selection and exclusion process. Seventy-five (75) articles that enrolled a total number of 1522 subjects treated with ACEIs, $\beta$-blockers, CCBs and thiazide diuretics were included [2-76].

For studies that measured PV, ${ }^{125}$ Iodine-labeled albumin was used. For studies that measured CO, the methodologies varied. Twenty-six studies used a dye dilution technique, 8 used Doppler ultrasound, 7 used the Fick technique, 5 used impedance cardiography, 1 used the indirect Fick technique, 1 used thermodilution, and 1 used technetium labeled albumin. For studies that measured SV, the methodologies also 
TABLE 1: Summary of the drug names searched in online databases.

\begin{tabular}{lcccc}
\hline & $\beta$-blockers & & ACEIs & CCBs \\
\hline acebutolol & carvedilol & metipranolol & captopril & amlodipine \\
alprenolol & celiprolol & metoprolol & benazapril & bepridil \\
amosulalol & cyanopindolol & nadolol & enalapril & diltiazem \\
arotinolol & dihydroalprenolol & nebivilol & fosinopril & felodipine \\
atenolol & epanolol & oxprenolol & lisinopril & isradipine \\
befunolol & esmolol & penbutolol & perindopril & nicardipine \\
betaxolol & exaprolol & pindolol & quinapril & nifedipine \\
bevantolol & flestolol & practolol & ramipril & nimodipine \\
bisoprolol & icatibant & prizidilol & & nisoldipine \\
bopindolol & indenolol & propranolol & & nitrendipine \\
bucindilol & iodpcyanaopindolol & sotalol & & verapamil \\
bufuralol & labetalol & talinolol & & \\
bupranolol & landiolol & tertatolol & & \\
butoxamine & levobunolol & tilisilol & & \\
carazolol & medroxalol & timolol & & \\
carteolol & mepindolol & tobanum & & \\
\hline
\end{tabular}

3974 citations identified using search terms

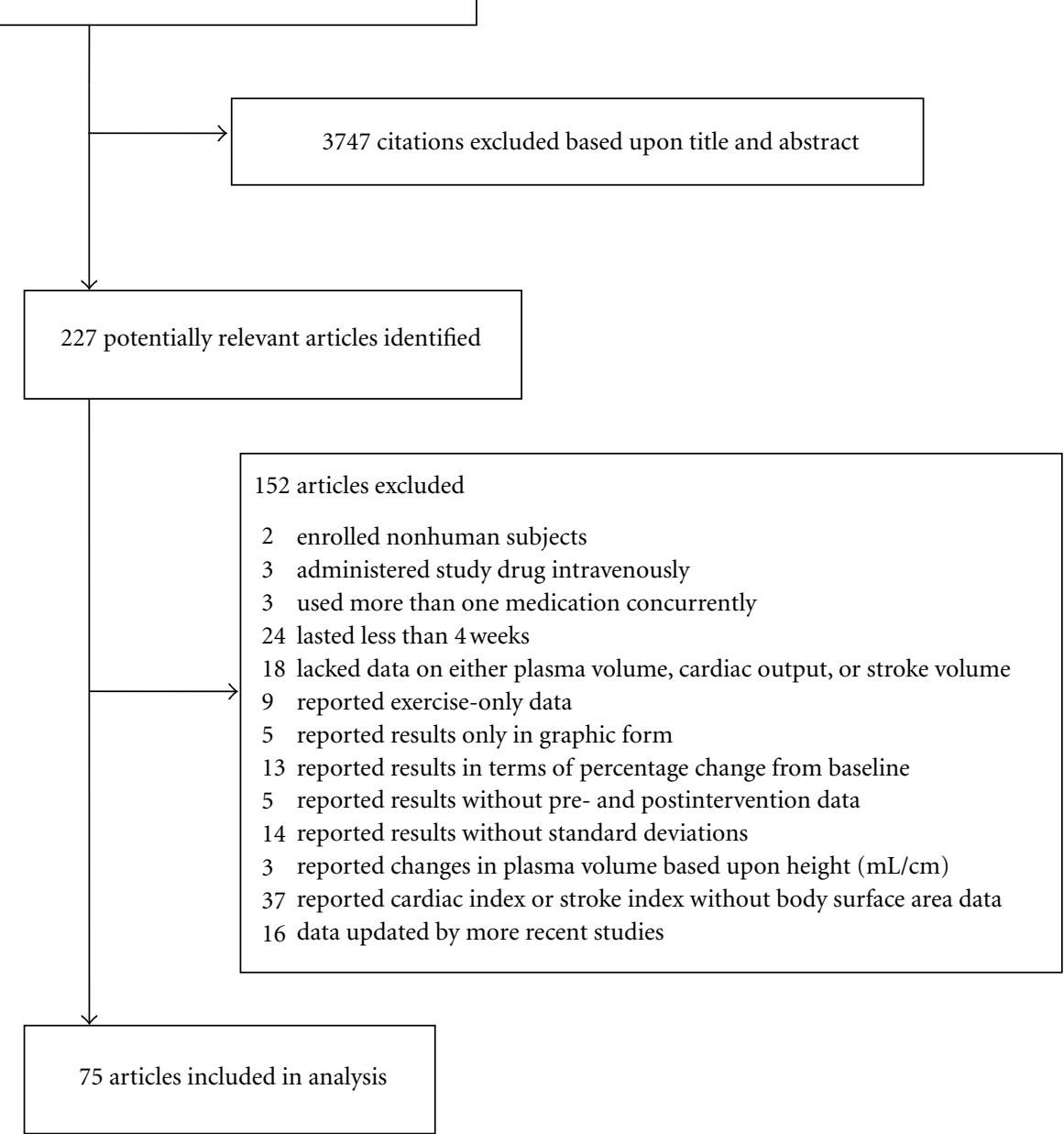

FIGURE 2: Summary of selection and exclusion process for meta-analysis articles. 


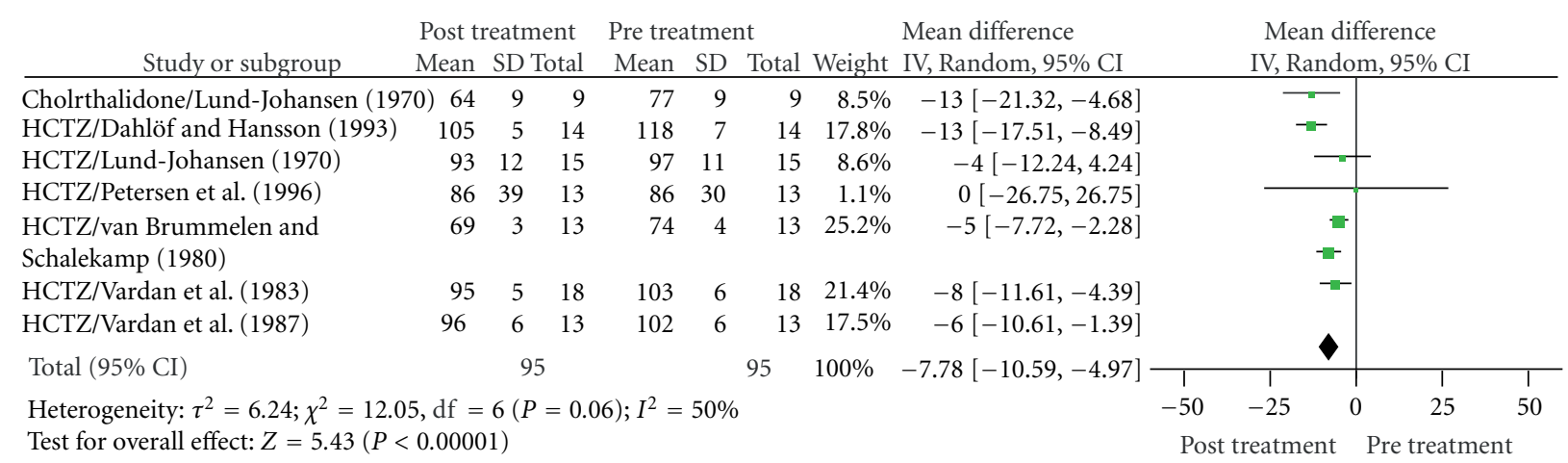

SD indicates standard deviation

MD indicates mean difference

FIGURE 3: Forest plot of change in stroke volume for thiazide diuretics.

varied. Ten used echocardiography, and 9 used multiple gated acquisition scans. Many of the studies that measured CO calculated SV. Likewise, many of the studies that measured SV calculated CO.

Table 2 summarizes the total number of studies and the total number of subjects for each hemodynamic variable according to class of antihypertensive medication. A few studies included data on more than one medication. Other studies reported more than one trial of a single medication, or else reported subgroups of a single medication trial that were best analyzed as separate trials.

3.2. Study Characteristics. The studies included in the metaanalysis enrolled men and women with uncomplicated hypertension. The majority of the subjects were men. Most of the studies did not mention the ethnicity or race of the subjects. When race or ethnicity was identified, the majority of the subjects were Caucasian. Subjects ranged from 18-87 years old, but most were between 30-60 years of age. Most of the studies did not mention exclusion criteria, but some of the studies specified exclusion criteria that included coronary artery disease, heart failure, chronic obstructive lung disease, renal disease, and diabetes mellitus.

3.3. Heterogeneity Analysis. The tests for heterogeneity were significant in the majority of analyses, indicating that a nonrandom model would be inadequate for the present study. Therefore, random effect estimates were used throughout the meta-analysis to protect against possible undetected heterogeneities.

$I^{2}$ index was used to account for variability in effect size estimates across the studies. The Tau-squared test was used to account for variance between the studies. The $I^{2}$ index for the data on SV for the different antihypertensive classes is $70 \%$ for the SV data on CCBs, 94\% for the SV data on ACEIs, 33\% for the data on $\beta$-blockers, and $50 \%$ for the SV data on thiazides. The SV data suggests low-to-moderate heterogeneity for the CCBs and ACEIs, and medium heterogeneity for the $\beta$ blockers and thiazides [77].
3.4. Quantitative Data Synthesis. Table 3 summarizes the changes in hemodynamic variables from baseline according to class of antihypertensive drug. A forest plot of the thiazide diuretic SV data (Figure 3) is representative of the data analysis used to construct Table 3.

ACEIs, CCBs, $\beta$-blockers, and thiazide diuretics all lowered MAP ( -16 [CI -24 to -9 ], -15 [CI -18 to -13 ], -14 [CI -16 to -13 ],-12 [CI -17 to -7$] \mathrm{mmHg}$, resp., $P<0.001$ for each).

$\beta$-blockers lowered HR ( -12 [CI -14 to -10 ] beats/ minute, $P<0.001)$. ACEIs, CCBs, and thiazide diuretics had no significant effect upon HR.

ACEIs raised PV (44 [CI 0.3 to 88 ] mL, $P<0.05$ ). $\beta$-blockers, CCBs, and thiazide diuretics had no significant effect upon PV.

$\beta$-blockers and thiazide diuretics decreased CO $(-0.65$ [CI -0.86 to -0.43$]$ lit $/ \mathrm{min}, P<0.001$, and -0.63 [CI -0.75 to -0.51$] \mathrm{lit} / \mathrm{min}, P<0.01$, resp.). ACEIs and CCBs had no significant effect upon CO.

CCBs and $\beta$-blockers increased SV (4 [CI 1 to 7] $\mathrm{mL}, P<$ 0.01 , and 4 [CI 3 to 6 ] $\mathrm{mL}, P<0.001$, resp.). Thiazide diuretics reduced SV $(-8[\mathrm{CI}-11$ to -5$] \mathrm{mL}, P<0.01)$. ACEIs had no significant effect upon SV.

In a subgroup analysis, dihydropyridine CCBs and nondihydropyridine CCBs both increased SV (5 [CI 1 to 9] $\mathrm{mL}$, $P=0.02$, versus 5 [CI 1 to 9 ] $\mathrm{mL}, P=0.02$, resp.).

\section{Discussion}

While all antihypertensive drugs lower BP, the various classes of antihypertensive medications differ in their effects upon other hemodynamic variables. $\beta$-blockers reduce $H R$ but none of the other classes of antihypertensive drugs do so. $\beta$ blockers and thiazide diuretics reduce cardiac output while ACEIs and CCBs have no effect upon CO. CCBs and $\beta$ blockers increase SV, thiazide diuretics decrease SV, and ACEIs have no effect upon SV. Our findings regarding ACEIs and $\mathrm{PV}$, and our findings regarding thiazide diuretics and SV may be noteworthy. 
TABLE 2: Summary of the number of studies and subjects included in meta-analysis according to antihypertensive medication class and hemodynamic category.

\begin{tabular}{llccccccccc}
\hline & \multicolumn{2}{c}{ MAP } & \multicolumn{2}{c}{ Heart rate } & \multicolumn{2}{c}{ Plasma volume } & \multicolumn{2}{c}{ Cardiac output } & \multicolumn{2}{c}{ Stroke volume } \\
& $n^{*}$ & $N^{* *}$ & $n^{*}$ & $N^{* *}$ & $n^{*}$ & $N^{* *}$ & $n^{*}$ & $N^{* *}$ & $n^{*}$ \\
\hline ACEIs & 18 & 277 & 16 & 231 & 6 & 78 & 14 & 212 & 14 & 198 \\
$\beta$-blockers & 29 & 591 & 25 & 591 & 8 & 150 & 25 & 581 & 16 & 411 \\
CCBs & 16 & 312 & 13 & 256 & 7 & 127 & 11 & 198 & 11 & 194 \\
Thiazides & 11 & 124 & 8 & 103 & 7 & 102 & 7 & 87 & 7 \\
\hline
\end{tabular}

${ }^{*} n=$ total number of studies.

${ }^{* *} \mathrm{~N}=$ total number of subjects.

TABLE 3: Mean changes in hemodynamic variables with confidence intervals.

\begin{tabular}{|c|c|c|c|c|c|}
\hline & $\begin{array}{l}\text { Change in MAP with } \\
\text { CI (mmHg) }\end{array}$ & Change in HR with CI & $\begin{array}{l}\text { Change in PV with CI } \\
(\mathrm{mL})\end{array}$ & $\begin{array}{l}\text { Change in CO with CI } \\
(\mathrm{lit} / \mathrm{min})\end{array}$ & $\begin{array}{c}\text { Change in SV } \\
\text { with CI } \\
(\mathrm{mL} / \text { stroke })\end{array}$ \\
\hline ACEIs & $-16(-24 \text { to }-9)^{\#}$ & $0.8(-0.4$ to 2$)$ & $44(0.3 \text { to } 88)^{*}$ & $0.10(-0.22$ to 0.44$)$ & $2(-3$ to 7$)$ \\
\hline$\beta$-blockers & $-14(-16 \text { to }-13)^{\#}$ & $-12(-14 \text { to }-10)^{\#}$ & $57(-23$ to 140$)$ & $-0.65(-0.86 \text { to }-0.43)^{\#}$ & $4(3 \text { to } 6)^{\#}$ \\
\hline CCBs & $-15(-18 \text { to }-13)^{\#}$ & $0.4(-2$ to 3$)$ & $59(-16$ to 130$)$ & $0.14(-0.10$ to 0.33$)$ & $4(1 \text { to } 7)^{* *}$ \\
\hline Thiazides & $-12(-17 \text { to }-7)^{\#}$ & $0(-2$ to 2$)$ & $-110(-290$ to 57$)$ & $\begin{array}{c}-0.63(-0.75 \text { to } \\
-0.51)^{* *}\end{array}$ & $-8(-11 \text { to }-5)^{* *}$ \\
\hline
\end{tabular}

${ }^{*} P<0.05$.

${ }^{* *} P<0.01$

${ }^{\#} P<0.001$.

ACEIs increase PV but none of the other classes of antihypertensive drugs change PV. The effect of ACEIs upon PV is surprising because ACEIs are not recognized as causing fluid retention [78]. To the extent that an increase in plasma volume results in an increase in intra-arterial volume, one would expect an increase in plasma volume to be accompanied by an increase in $\mathrm{CO}$, assuming that there is a corresponding increase in intra-arterial volume [7981]. Since our study found that ACEIs are not associated with an increase in $\mathrm{CO}$ despite an increase in $\mathrm{PV}$, perhaps the vasodilatation that accompanies angiotensin converting enzyme inhibition involves the venous circulation rather than the arterial circulation [78].

If all antihypertensive drug classes reduce the risk of adverse cardiovascular events comparably, as a recent metaanalysis determined [82], then distinguishing hemodynamic differences between the different categories of antihypertensive medications has little clinical significance. On the other hand, since a network meta-analysis found that lowdose diuretics are the most effective first-line treatment for preventing the occurrence of cardiovascular disease morbidity and mortality [83], then factors apart from BP reduction may be clinically relevant. Because all categories of antihypertensive medications lower BP equivalently [84], differences in other hemodynamic properties may be significant. In particular, our finding that diuretics lower SV, whereas other antihypertensive medications do not, may be noteworthy because reductions in SV would be expected to reduce the likelihood of turbulent blood flow, thereby slowing the progression of atherosclerotic cardiovascular disease [85].
There are several limitations of this meta-analysis. Most of the studies included in the meta-analysis enrolled less than 20 subjects. When subjects are stratified by hemodynamic variable and drug class, the number of subjects in many of the categories is modest: many of the categories include less than 200 subjects, and several categories include less than 100 subjects. Another limitation is that most of the studies included in the meta-analysis compared an antihypertensive drug to placebo or no treatment, but few studies compared one antihypertensive medication with another. Accordingly, the data allow one to make qualitative comparisons of the hemodynamic properties of the different classes of antihypertensive medications. As a result, one can say that one class of medication decreases $\mathrm{CO}$ while another class does not. However, the data do not allow quantitative comparisons of the magnitude of the effect between the different classes of antihypertensive medications. Consequently, the results do not allow one to say that one class of medication lowers BP more than another, nor do the results allow one to say that one class of medication raises SV more than another. It is a limitation of this study that the variability in the CO and SV measures due to a wide variation in methodologies used could not be taken into account in the model.

The lack of uniform drug dosage within all four categories of antihypertensive medications limits identifying precisely the hemodynamic effect of the different medications. Variability in dosage may be especially relevant to thiazide diuretics because the dose of these drugs in many of the trials was higher than the doses that are typically used in contemporary medical practice [86]. Accordingly, the 
magnitude of the hemodynamic effects of thiazide diuretics as they are currently prescribed are unlikely to be the same as the magnitude of the hemodynamic effects of thiazide diuretics at the doses used in the studies included in this metaanalysis. Even though the magnitude of any hemodynamic effect would be expected to be dose dependent, the qualitative direction of that effect would not be expected to be dose dependent.

An additional limitation is that we excluded studies that enrolled subjects with diabetes, heart failure, and coronary artery disease. Therefore, our results may not be generalizable to hypertensive patients with these comorbidities. It is possible that we missed some studies by limiting the study to English language publications. However, there were only a dozen non-English language studies that were identified by the initial search strategy, only two of which contained data that appeared as if it might be relevant to the metaanalysis, and we could not be certain that we could accurately extract the relevant data. It is also a limitation that our results reflect a publication bias since we did not attempt to locate unpublished data. Finally, it is a limitation that we could not incorporate the many studies that reported cardiac index and stroke volume index data, but which did not report cardiac output or stroke volume data.

In summary, in the treatment of uncomplicated hypertension, the various classes of antihypertensive medications differ from each other in terms of their non-blood-pressurelowering hemodynamic properties.

\section{Conflict of Interests}

The authors report no potential conflict of interests with any companies/organizations whose products or services may be discussed in this paper.

\section{References}

[1] J. L. Hodges and E. L. Lehmann, Basic Concepts of Probability and Statistics, Holden-Day, San Francisco, Calif, USA, 2nd edition, 1970.

[2] S. N. Hunyor, A. J. Zweifler, L. Hansson, M. A. Schork, and C. Ellis, "Effect of high dose spironolactone and chlorthalidone in essential hypertension: relation to plasma renin activity and plasma volume," Australian and New Zealand Journal of Medicine, vol. 5, no. 1, pp. 17-24, 1975.

[3] P. Lund-Johansen, "Hemodynamic changes in long-term diuretic therapy of essential hypertension. A comparative study of chlorthalidone, polythiazide and hydrochlorothiazide," Acta Medica Scandinavica, vol. 187, no. 6, pp. 509-518, 1970.

[4] S. Shah, I. Khatri, and E. D. Freis, "Mechanism of antihypertensive effect of thiazide diuretics," American Heart Journal, vol. 95, no. 5, pp. 611-618, 1978.

[5] R. J. Solomon, N. Stillman, and M. S. Weinberg, "Thiazide induced hypotension: the role of plasma volume reduction and the urinary kallikrein system," Advances in Experimental Medicine and Biology, vol. 198, pp. 243-251, 1986.

[6] P. van Brummelen and M. A. D. H. Schalekamp, "Body fluid volumes and response of renin and aldosterone to short- and long-term thiazide therapy of essential hypertension," Acta Medica Scandinavica, vol. 207, no. 4, pp. 259-264, 1980.
[7] P. van Brummelen, A. J. Man In 'T Veld, and M. A. D. H. Schalekamp, "Hemodynamic changes during long-term thiazide treatment of essential hypertension in responders and nonresponders," Clinical Pharmacology and Therapeutics, vol. 27, no. 3, pp. 328-336, 1980.

[8] S. Vardan, M. H. Dunsky, N. E. Hill et al., "Effect of one year of thiazide therapy on plasma volume, renin, aldosterone, lipids and urinary metanephrines in systolic hypertension of elderly patients," American Journal of Cardiology, vol. 60, no. 4, pp. 388-390, 1987.

[9] S. Vardan, S. Mookherjee, R. Warner, and H. Smulyan, "Systolic hypertension in the elderly. Hemodynamic response to longterm thiazide diuretic therapy and its side effects," The Journal of the American Medical Association, vol. 250, no. 20, pp. 2807-2813, 1983.

[10] P. A. Freier, G. L. Wollam, W. Dallas Hall, D. J. Unger, M. B. Douglas, and R. P. Bain, "Blood pressure, plasma volume, and catecholamine levels during enalapril therapy in blacks with hypertension," Clinical Pharmacology and Therapeutics, vol. 36, no. 6, pp. 731-737, 1984.

[11] B. Dahlöf and L. Hansson, "The influence of antihypertensive therapy on the structural arteriolar changes in essential hypertension: different effects of enalapril and hydrochlorothiazide," Journal of Internal Medicine, vol. 234, no. 3, pp. 271-279, 1993.

[12] J. R. Petersen, H. Drabaek, G. Gleerup, J. Mehlsen, L. J. Petersen, and K. Winther, "ACE inhibition with spirapril improves diastolic function at rest independent of vasodilation during treatment with spirapril in mild to moderate hypertension," Angiology, vol. 47, no. 3, pp. 233-240, 1996.

[13] K. Landmark, M. Forsman, K. Lindberg et al., "Nitrendipine and mefruside in elderly hypertensives: effects on blood pressure, cardiac output, cerebral blood flow and metabolic parameters," Journal of Human Hypertension, vol. 9, no. 4, pp. 281-285, 1995.

[14] J. E. Otterstad, G. Froeland, A. K. W. Soeyland, K. M. Knutsen, and T. Ekeli, "Changes in left ventricular dimensions and systolic function in 100 mildly hypertensive men during one year's treatment with atenolol versus hydrochlorothiazide and amiloride (moduretic): a double-blind, randomized study," Journal of Internal Medicine, vol. 231, no. 5, pp. 493-501, 1992.

[15] R. Fagard, A. Amery, T. Reybrouck, P. Lunen, and L. Billiet, "Acute and chronic systemic and pulmonary hemodynamic effects of angiotensin converting enzyme inhibition with captopril in hypertensive patients," American Journal of Cardiology, vol. 46, no. 2, pp. 295-300, 1980.

[16] F. M. Fouad, R. C. Tarazi, E. L. Bravo, and S. C. Textor, "Hemodynamic and antihypertensive effects of the new oral angiotensin-converting-enzyme inhibitor MK-421 (enalapril)," Hypertension, vol. 6, no. 2, pp. 167-174, 1984.

[17] G. E. Garavaglia, F. H. Messerli, B. D. Nunez, R. E. Schmieder, and E. D. Frohlich, "Immediate and short-term cardiovascular effects of a new converting enzyme inhibitor (lisinopril) in essential hypertension," American Journal of Cardiology, vol. 62, no. 13, pp. 912-916, 1988.

[18] E. Grossman, F. H. Messerli, S. Oren, F. Soria, and R. E. Schmieder, "Disparate cardiovascular response to stress tests during isradipine and fosinopril therapy," American Journal of Cardiology, vol. 72, no. 7, pp. 574-579, 1993.

[19] R. K. Gupta, S. E. Kjeldsen, L. Krause et al., "Hemodynamic effects of quinapril, a novel angiotensin-converting enzyme inhibitor," Clinical Pharmacology and Therapeutics, vol. 48, no. 1, pp. 41-49, 1990. 
[20] P. Lund-Johansen and P. Omvik, "Long-term haemodynamic effects of enalapril (alone and in combination with hydrochlorothiazide) at rest and during exercise in essential hypertension," Journal of Hypertension-Supplement, vol. 2, no. 2, pp. S49-S56, 1984.

[21] S. Oren, F. H. Messerli, E. Grossman, G. E. Garavaglia, and E. D. Frohlich, "Immediate and short-term cardiovascular effects of fosinopril, a new angiotensin-converting enzyme inhibitor, in patients with essential hypertension," Journal of the American College of Cardiology, vol. 17, no. 5, pp. 1183-1187, 1991.

[22] B. Ricciardelli, M. Volpe, B. Trimarco et al., "Haemodynamic and clinical effects of long-term treatment of essential hypertension with captopril," European Heart Journal, vol. 4, no. 7, pp. 496-501, 1983.

[23] D. E. Uehlinger, C. P. Ferrier, R. Matthieu et al., "Antihypertensive contribution of sodium depletion and the sympathetic axis during chronic angiotensin II converting enzyme inhibition," Journal of Hypertension, vol. 7, no. 11, pp. 901-907, 1989.

[24] E. Valvo, L. Gammaro, V. Bedogna et al., "Systemic and renal hemodynamic changes after two-month treatment with enalapril in patients with essential hypertension," International Journal of Clinical Pharmacology Therapy and Toxicology, vol. 25, no. 12, pp. 656-659, 1987.

[25] E. Valvo, P. Casagrande, V. Bedogna et al., "Systemic and renal effects of a new angiotensin converting enzyme inhibitor, benazepril, in essential hypertension," Journal of Hypertension, vol. 8, no. 11, pp. 991-995, 1990.

[26] R. M. Zusman, D. M. Christensen, J. Higgins, and C. A. Boucher, "Effects of fosinopril on cardiac function in patients with hypertension. Radionuclide assessment of left ventricular systolic and diastolic performance," American Journal of Hypertension, vol. 5, no. 4 I, pp. 219-223, 1992.

[27] G. G. Rogers, C. Rosendorff, C. Goodman, and H. M. Radford, "Effects of angiotensin converting enzyme inhibition and $\beta$ blockade on exercise responses in hypertensive patients," Journal of Hypertension, vol. 6, no. 4, pp. S662-S665, 1988.

[28] I. C. Haznedaroglu, Y. Erdem, L. Tokgözoglu et al., "Effects of ace inhibition on left ventricular dimensions and haemodynamics in systemic hypertension: a radionuclide and echocardiographic study," Central African Journal of Medicine, vol. 41, no. 4, pp. 118-123, 1995.

[29] J. Soma, S. Aakhus, K. Dahl, T. E. Widerøe, and T. Skjærpe, "Total arterial compliance in ambulatory hypertension during selective $\beta 1$-adrenergic receptor blockade and angiotensinconverting enzyme inhibition," Journal of Cardiovascular Pharmacology, vol. 33, no. 2, pp. 273-279, 1999.

[30] R. M. Zusman, D. M. Christensen, J. Higgins, and C. A. Boucher, "Comparison of the cardiac and hemodynamic effects of lisinopril and atenolol in patients with hypertension: therapeutic implications," Journal of Cardiovascular Pharmacology, vol. 20, no. 2, pp. 216-222, 1992.

[31] O. K. Andersson, B. Persson, B. R. Widgren, and M. Wysocki, "Central hemodynamics and brachial artery compliance during therapy with isradipine, a new calcium antagonist," Journal of Cardiovascular Pharmacology, vol. 15, supplement 1, pp. S87-S89, 1990.

[32] N. E. Bruun, H. Ibsen, F. Nielsen, M. D. Nielsen, A. G. Mølbak, and O. J. Hartling, "The influence of nifedipine treatment on counter-regulatory mechanisms in essential hypertension," Journal of Hypertension, vol. 3, no. 3, pp. S223-S225, 1985.
[33] F. M. Fouad, R. Pedrinelli, and E. L. Bravo, "Clinical and systemic hemodynamic effects of nitrendipine," Clinical Pharmacology and Therapeutics, vol. 35, no. 6, pp. 768-775, 1984.

[34] E. D. Frohlich, M. J. McLoughlin, C. J. Losem, R. Ketelhut, and F. H. Messerli, "Hemodynamic comparison of two nifedipine formulations in patients with essential hypertension," American Journal of Cardiology, vol. 68, no. 13, pp. 1346-1350, 1991.

[35] E. Grossman, S. Oren, G. E. Garavaglia, F. H. Messerli, and E. D. Frohlich, "Systemic and regional hemodynamic and humoral effects of nitrendipine in essential hypertension," Circulation, vol. 78, no. 6, pp. 1394-1400, 1988.

[36] E. Grossman, F. H. Messerli, S. Oren, B. Nunez, and G. E. Garavaglia, "Cardiovascular effects of isradipine in essential hypertension," American Journal of Cardiology, vol. 68, no. 1, pp. 65-70, 1991.

[37] P. Lund-Johansen, P. Omvik, W. White et al., "Long-term haemodynamic effects of amlodipine at rest and during exercise in essential hypertension," Journal of Hypertension, vol. 8, no. 12, pp. 1129-1136, 1990.

[38] P. Lund-Johansen and P. Omvik, "Chronic hemodynamic effects of tiapamil and felodipine in essential hypertension at rest and during exercise," Journal of Cardiovascular Pharmacology, vol. 15, supplement 4, pp. S42-S47, 1990.

[39] C. Marone, S. Luisoli, and F. Bomio, "Body sodium-blood volume state, aldosterone, and cardiovascular responsiveness after calcium entry blockade with nifedipine," Kidney International, vol. 28, no. 4, pp. 658-665, 1985.

[40] C. Mazzola, C. Borgnino, D. Colombo et al., "Antihypertensive and hemodynamic effects of slow-release nicardipine," International Journal of Clinical Pharmacology Therapy and Toxicology, vol. 26, no. 10, pp. 503-508, 1988.

[41] S. Oren, E. Gossman, and E. D. Frohlich, "Effects of calcium entry blockers on distribution of blood volume," American Journal of Hypertension, vol. 9, no. 7, pp. 628-632, 1996.

[42] R. E. Schmieder, F. H. Messerli, G. E. Garavaglia, and B. D. Nunez, "Cardiovascular effects of verapamil in patients with essential hypertension," Circulation, vol. 75, no. 5, pp. 1030-1036, 1987.

[43] D. B. Toftdahl and G. S. Andersen, "Effect of long-term nifedipine treatment on body fluid composition in essential hypertension," Journal of Human Hypertension, vol. 3, no. 3, pp. 203-206, 1989.

[44] T. C. K. Tham, N. Herity, S. Guy, and B. Silke, "Haemodynamic comparison of amlodipine and atenolol in essential hypertension using the quantascope," British Journal of Clinical Pharmacology, vol. 36, no. 6, pp. 555-560, 1993.

[45] C. V. S. Ram, D. G. Gonzalez, W. Featherston, C. Lugo, J. Ralakis, and N. M. Kaplan, "Nicardipine and propranolol in the treatment of hypertension: similar antihypertensive but dissimilar hemodynamic actions," American Heart Journal, vol. 119, no. 2, pp. 463-467, 1990.

[46] V. Vulpis, T. M. Seccia, S. Ricci, M. D. Lograno, E. Daniele, and A. Pirrelli, "Non-invasive haemodynamic study in hypertensive subjects after treatment with verapamil slow release," Pharmacological Research, vol. 30, no. 2, pp. 153-160, 1994.

[47] A. Amery, L. Billiet, A. Boel, R. Fagard, T. Reybrouck, and J. Willems, "Mechanism of hypotensive effect during beta adrenergic blockade in hypertensive patients. Hemodynamic and renin response to a new cardioselective agent: Tenormin or ICI 66,082," American Heart Journal, vol. 91, no. 5, pp. 634-642, 1976. 
[48] G. S. Andersen, O. J. Hartling, H. O. Hein, and A. Leth, "Changes in blood pressure, fluid volumes and glomerular filtration rate during long-term treatment with prizidilol, an antihypertensive drug with combined vasodilatator and $\beta$ adrenoceptor blocking actions," Danish Medical Bulletin, vol. 32, no. 5, pp. 280-283, 1985.

[49] N. de Luca, B. Ricciardelli, G. Groothold, A. Cuocolo, M. Volpe, and B. Trimarco, "Changes in left ventricular anatomy and systemic hemodynamics induced by antihypertensive therapy with indenolol," Journal of clinical hypertension, vol. 3, no. 2, pp. 125-134, 1987.

[50] G. R. Dreslinski, F. H. Messerli, F. G. Dunn, D. H. Suarez, E. Reisin, and E. D. Frohlich, "Hemodynamics, biochemical and reflexive changes produced by atenolol in hypertension," Circulation, vol. 65, no. 7, pp. 1365-1368, 1982.

[51] A. G. Dupont, P. Vanderniepen, A. M. Bossuyt, M. H. Jonckheer, and R. O. Six, "Nadolol in essential hypertension: effect on ambulatory blood pressure, renal haemodynamics and cardiac function," British Journal of Clinical Pharmacology, vol. 20, no. 2, pp. 93-99, 1985.

[52] R. C. Edwards and E. B. Raftery, "Haemodynamic effects of long term oral labetalol," British Journal of Clinical Pharmacology, vol. 3, no. 4, supplement 3, pp. 733S-736S, 1976.

[53] M. C. Fahrenbach, S. M. Yurgalevitch, J. M. Zmuda, and P. D. Thompson, "Effect of doxazosin or atenolol on exercise performance in physically active, hypertensive men," American Journal of Cardiology, vol. 75, no. 4, pp. 258-263, 1995.

[54] R. Fariello, C. L. Alicandri, E. Agabiti-Rosei et al., "Effects of prizidilol (SKF 92657) on blood pressure, haemodynamics, sympathetic nervous system activity and plasma volume in essential hypertension," Clinical Science, vol. 61, supplement 7, pp. 465s-468s, 1981.

[55] P. Fitscha, W. Meisner, G. Brandstetter, and B. Tiso, "Haemodynamic effects of short-term treatment with bopindolol in essential hypertension," European Journal of Clinical Pharmacology, vol. 34, no. 4, pp. 411-413, 1988.

[56] E. D. Frohlich, F. H. Messerli, G. R. Deslinski, and I. Kobrin, "Long-term renal hemodynamic effects of nadolol in patients with essential hypertension," American Heart Journal, vol. 108, no. 4, pp. 1141-1143, 1984.

[57] M. Frisk Holmberg, L. Jorfeldt, and A. Juhlin-Dannfeldt, "Influence of alprenolol on hemodynamic and metabolic responses to prolonged exercise in subjects with hypertension," Clinical Pharmacology and Therapeutics, vol. 21, no. 6, pp. 675-684, 1977.

[58] M. Frisk-Holmberg, A. Juhlin-Dannfelt, and H. Aström, "Haemodynamic and metabolic responses to prolonged exercise after chronic $\beta 1$-adrenoceptor blockade in hypertensive man," Clinical Physiology, vol. 5, no. 3, pp. 231-242, 1985.

[59] S. N. Hunyor, G. E. Bauer, M. Ross, and H. Larkin, "Labetalol and propranolol in mild hypertensives: comparison of blood pressure and plasma volume effects," Australian and New Zealand Journal of Medicine, vol. 10, no. 2, pp. 162-166, 1980.

[60] M. Leeman, P. van de Borne, F. Collart et al., "Bisoprolol and atenolol in essential hypertension: effects on systemic and renal hemodynamics and on ambulatory blood pressure," Journal of Cardiovascular Pharmacology, vol. 22, no. 6, pp. 785-791, 1993.

[61] P. Lund-Johansen, "Central haemodynamic effects of beta blockers in hypertension. A comparison between atenolol, metoprolol, timolol, penbutolol, alprenolol pindolol and bunitrolol," European Heart Journal, vol. 4, pp. 1S-12S, 1983.
[62] P. Lund-Johansen and O. M. Bakke, "Haemodynamic effects and plasma concentrations of labetalol during long-term treatment of essential hypertension," British Journal of Clinical Pharmacology, vol. 7, no. 2, pp. 169-174, 1979.

[63] P. Lund-Johansen and P. Omvik, "Acute and chronic hemodynamic effects of drugs with different actions on adrenergic receptors: a comparison between alpha blockers and different types of beta blockers with and without vasodilating effect," Cardiovascular Drugs and Therapy, vol. 5, no. 3, pp. 605-616, 1991.

[64] P. Lund-Johansen and O. J. Ohm, "Haemodynamic long term effects of metoprolol at rest and during exercise in essential hypertension," British Journal of Clinical Pharmacology, vol. 4, no. 2, pp. 147-151, 1977.

[65] P. Lund-Johansen and O. J. Ohm, "Haemodynamic long term effects of $\beta$ receptor blocking agents in hypertension: a comparison between alprenolol, atenolol, metoprolol and timolol," Clinical Science and Molecular Medicine, vol. 51, no. 3, pp. 481S-483S, 1976.

[66] P. Lund-Johansen and P. Omvik, "Prizidilol in essential hypertension: long-term effects on plasma volume, extracellular fluid volume, and central hemodynamics at rest and during exercise," Journal of Cardiovascular Pharmacology, vol. 4, no. 6, pp. 1012-1017, 1982.

[67] P. Lund-Johansen and P. Omvik, "Chronic haemodynamic effects of carvedilol in essential hypertension at rest and during exercise," European Heart Journal, vol. 13, no. 2, pp. 281-286, 1992.

[68] E. Malacco, F. Mailland, E. Bosisio et al., "Acute and longterm haemodynamic effects of propranolol and indenolol in hypertension," European Journal of Clinical Pharmacology, vol. 30, no. 2, pp. 157-160, 1986.

[69] P. Omvik and P. Lund-Johansen, "The initial hemodynamic response to newer antihypertensive agents at rest and during exercise: review of visacor, doxazosin, nisoldipine, tiapamil, perindoprilat, pinacidil, dilevalol, and carvedilol," Cardiovascular Drugs and Therapy, vol. 4, no. 4, pp. 1135-1144, 1990.

[70] L. Poirier, J. Cléroux, A. Nadeau, and Y. Lacourcière, "Effects of nebivolol and atenolol on insulin sensitivity and haemodynamics in hypertensive patients," Journal of Hypertension, vol. 19, no. 8, pp. 1429-1435, 2001.

[71] S. Rasmussen and P. E. Nielsen, "Blood pressure, body fluid volumes and glomerular filtration rate during treatment with labetalol in essential hypertension," British Journal of Clinical Pharmacology, vol. 12, no. 3, pp. 349-353, 1981.

[72] S. Rasmussen and K. Rasmussen, "Influence of metoprolol, alone and in combination with a thiazide diuretic, on blood pressure, plasma volume, extracellular volume and glomerular filtration rate in essential hypertension," European Journal of Clinical Pharmacology, vol. 15, no. 5, pp. 305-310, 1979.

[73] B. Trimarco, A. Cuocolo, G. Groothold et al., "Indenolol: a new antihypertensive agent: efficacy, toxicity, and hemodynamic effects in a crossover double-blind study with metoprolol," Journal of Clinical Pharmacology, vol. 25, no. 5, pp. 328-336, 1985.

[74] K. Weber, T. Bohmeke, R. van der Does, and S. H. Taylor, "Hemodynamic differences between metoprolol and carvedilol in hypertensive patients," American Journal of Hypertension, vol. 11, no. 5, pp. 614-617, 1998.

[75] J. Wikstrand, B. Trimarco, G. Buzzetti et al., "Increased cardiac output and lowered peripheral resistance during metoprolol 
treatment," Acta Medica Scandinavica, vol. 214, no. 672, pp. 105-110, 1983.

[76] M. Galderisi, A. D’Errico, M. Sidiropulos, P. Innelli, O. de Divitiis, and G. de Simone, "Nebivolol induces parallel improvement of left ventricular filling pressure and coronary flow reserve in uncomplicated arterial hypertension," Journal of Hypertension, vol. 27, no. 10, pp. 2108-2115, 2009.

[77] T. B. Huedo-Medina, J. Sánchez-Meca, F. Marín-Martínez, and J. Botella, "Assessing heterogeneity in meta-analysis: Q statistic or I2 index?” Psychological Methods, vol. 11, no. 2, pp. 193-206, 2006.

[78] G. H. Williams, "Converting-enzyme inhibitors in the treatment of hypertension," The New England Journal of Medicine, vol. 319, no. 23, pp. 1517-1525, 1988.

[79] R. P. Blankfield, "Implications of calculated intravascular volume changes upon atherosclerotic cardiovascular disease," Clinical Hemorheology and Microcirculation, vol. 38, no. 2, pp. 75-81, 2008.

[80] A. Kumar, R. Anel, E. Bunnell et al., "Preload-independent mechanisms contribute to increased stroke volume following large volume saline infusion in normal volunteers: a prospective interventional study," Critical Care, vol. 8, no. 3, pp. R128-R136, 2004.

[81] A. Kumar, R. Anel, E. Bunnell et al., "Effect of large volume infusion on left ventricular volumes, performance and contractility parameters in normal volunteers," Intensive Care Medicine, vol. 30, no. 7, pp. 1361-1369, 2004.

[82] F. Turnbull and Blood Pressure Lowering Treatment Trialists' Collaboration, "Effects of different blood-pressurelowering regimens on major cardiovascular events: results of prospectively-designed overviews of randomised trials," The Lancet, vol. 362, no. 9395, pp. 1527-1535, 2003.

[83] B. M. Psaty, T. Lumley, C. D. Furberg et al., "Health outcomes associated with various antihypertensive therapies used as first-line agents: a network meta-analysis," The Journal of the American Medical Association, vol. 289, no. 19, pp. 2534-2544, 2003.

[84] F. Turnbull and Blood Pressure Lowering Treatment Trialists' Collaboration, "Effects of different blood pressure-lowering regimens on major cardiovascular events in individuals with and without diabetes mellitus: results of prospectively designed overviews of randomized trials," Archives of Internal Medicine, vol. 165, no. 12, pp. 1410-1419, 2005.

[85] R. P. Blankfield, "Calculated effect of fluid retention upon velocity of blood flow and turbulence: implications for atherosclerosis," Clinical Hemorheology and Microcirculation, vol. 47, no. 2, pp. 79-86, 2011.

[86] M. E. Ernst and M. Moser, "Drug therapy: use of diuretics in patients with hypertension," The New England Journal of Medicine, vol. 361, no. 22, pp. 2153-2164, 2009. 


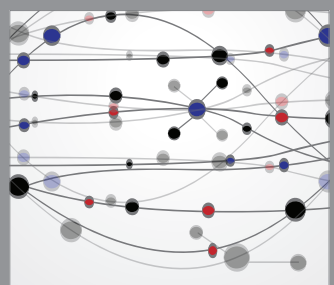

The Scientific World Journal
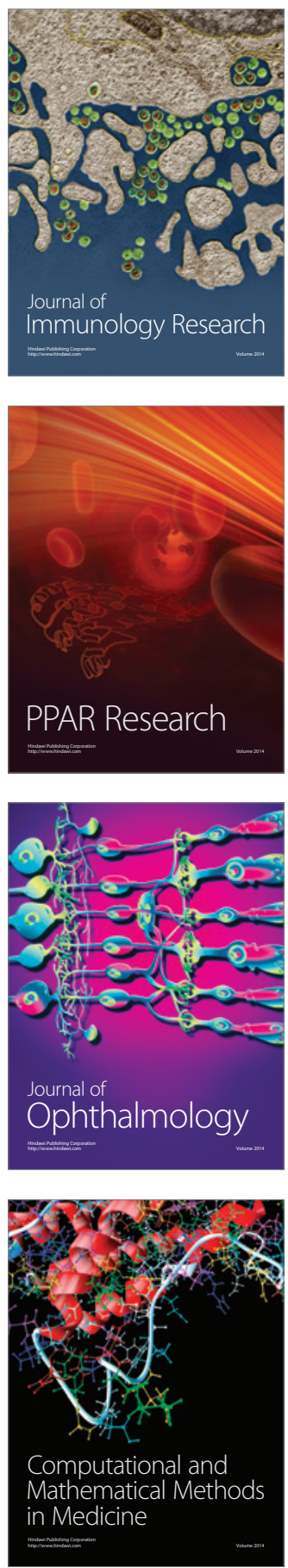

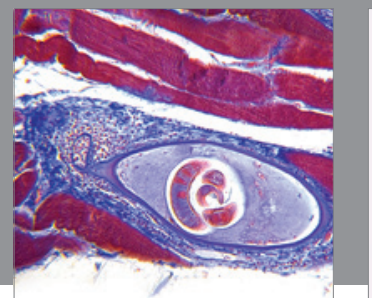

Gastroenterology

Research and Practice
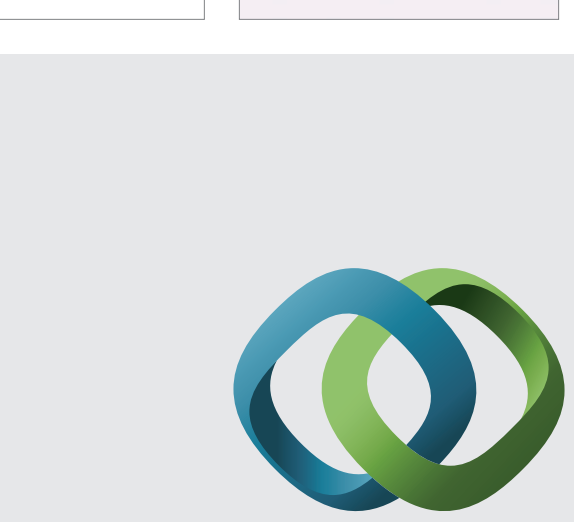

\section{Hindawi}

Submit your manuscripts at

http://www.hindawi.com
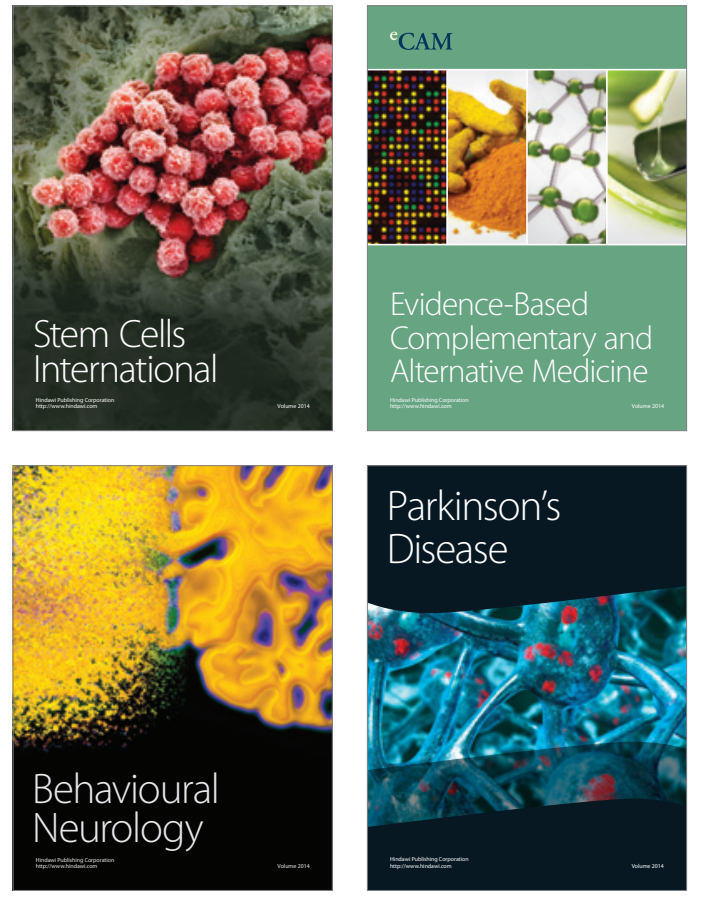
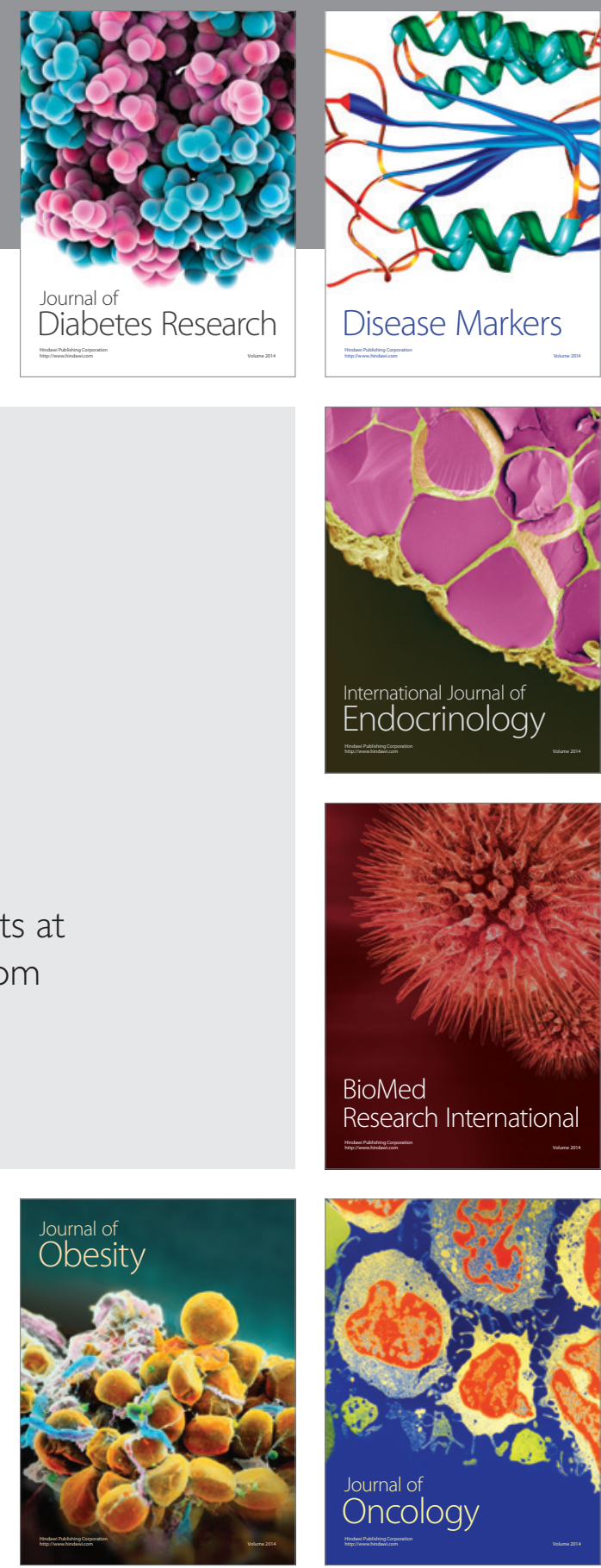

Disease Markers
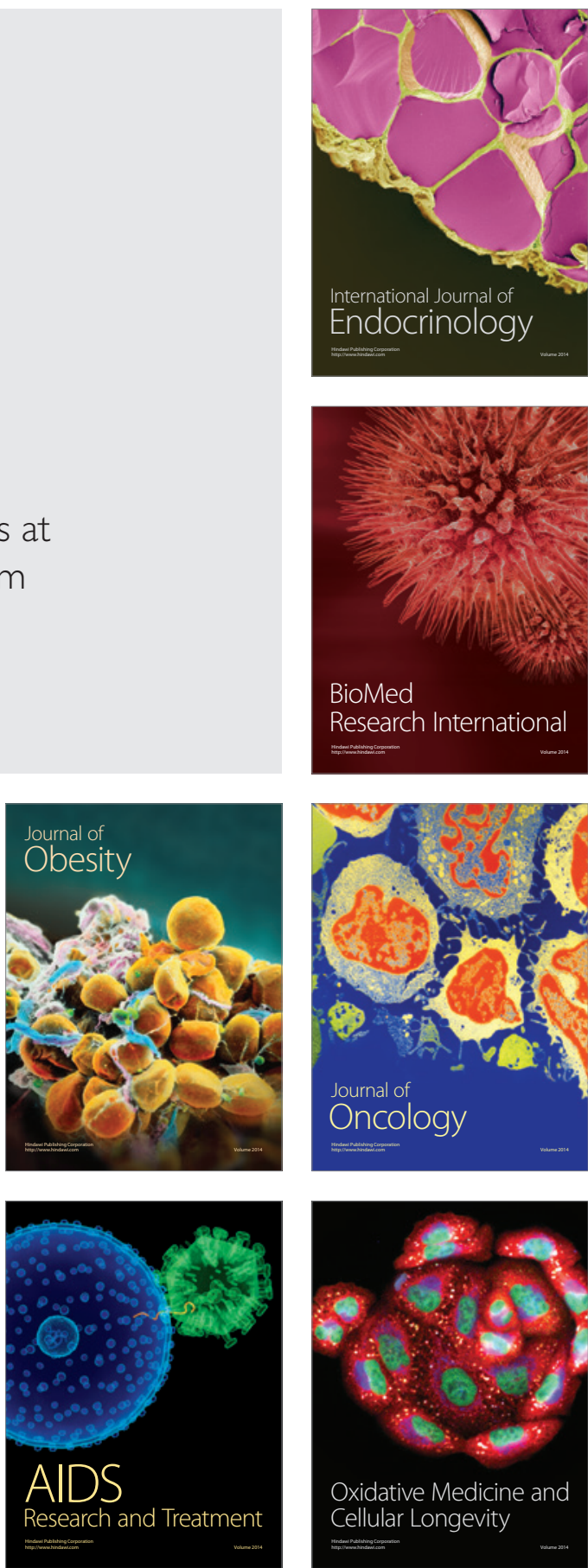